\title{
Modification of three point linkage system of medium tractor drawn sowing machine to operate by mini tractor
}

R. Swarnkar, Kapil Mandloi and Yagnik C. Yoganandi

Received : 26.05.2017; Revised : 12.03.2018; Accepted : 23.03.2018

See end of the Paper for authors' affiliation

Correspondence to :

Kapil Mandloi Department of Farm Machinery and Power Engineering, College of Agricultural Engineering and Technology (A.A.U.), Godhra (Gujarat) India
-ABSTRACT : The study of the three point linkage system of the sowing machine revealed that the sowing machines can be easily operated by the mini tractor, if the specification of three point linkage system were standardized as: Optimum distance between lower hitching points should be kept as $70 \mathrm{~cm}$ and Vertical distance between the hitching system of top link and lower link should be made at $60 \mathrm{~cm}$. These three point linkage systems provide versatility of use of the different farm tractors viz., Mini as well as medium size tractors. During the operation front ballasting of the mini tractor was required according to the weight of sowing machine however $100 \mathrm{~kg}$ front blasting was found appropriate. The manufacturers were requested to adopt the specification of the hitching system for fabricating new sowing machines it will enables to use the machine either by the medium tractor or mini tractor.

- KEY WORDS : Three point linkage system, Sowing machine, Mini tractor

- HOW TO CITE THIS PAPER : Swarnkar, R., Mandloi, Kapil and Yoganandi, Yagnik C. (2018). Modification of three point linkage system of medium tractor drawn sowing machine to operate by mini tractor. Internat. J. Agric. Engg., 11(1) : 249-256, DOI: 10.15740/HAS/IJAE/11.1/249-256. 